\title{
Editorial: Advances and Trends in Development of Plant Factories
}

\author{
Alejandro I. Luna-Maldonado *, Juan A. Vidales-Contreras * and \\ Humberto Rodríguez-Fuentes *
}

Department of Agricultural and Food Engineering, Faculty of Agriculture, Autonomous University of Nuevo Leon, Nuevo Leon, Mexico

Keywords: plant factories, intelligent systems, environment controlled and optimization, pharmaceuticals, genetic engineering, biofertilizers

\section{Editorial on Research Topic}

\section{Advances and Trends in Development of Plant Factories}

The plant factory is a facility that aids the steady production of high-quality vegetables all year round by artificially controlling the cultivation environment (e.g., light, temperature, humidity, carbon dioxide concentration, and culture solution), allowing growers to plan production. By controlling the internal environment, plant factories can produce vegetables about two to four times faster than by typical outdoor cultivation. In addition, as multiple cultivation shelves (a multi-shelf system) are used, the mass production of vegetables in a small space is facilitated.

\section{OPEN ACCESS}

Edited and reviewed by: Diego Rubiales, Spanish National Research Council,

Spain

*Correspondence: Alejandro I. Luna-Maldonado alejandro.lunam/@uanl.edu.mx

Juan A. Vidales-Contreras juan.vidalescn@uanl.edu.mx Humberto Rodríguez-Fuentes humberto.rodriguezfn@uanl.edu

Specialty section:

This article was submitted to Crop Science and Horticulture, a section of the journal Frontiers in Plant Science

Received: 31 October 2016 Accepted: 23 November 2016 Published: 09 December 2016

Citation:

Luna-Maldonado Al,

Vidales-Contreras JA and Rodríguez-Fuentes H (2016) Editorial: Advances and Trends in Development of Plant Factories.

Front. Plant Sci. 7:1848. doi: 10.3389/fpls.2016.01848
This research topic presents some new trends on intelligent measuring systems; environment controlled and optimization; flavonoids; phenylpropanoids, transcriptomes, and bacteria.

Among some of the new findings on intelligent measuring systems, Chen et al. developed an automated measurement system to measure and record the plant weight during plant growth in plant factory. They found that plant weights measured by the weight measurement device are highly correlated with the weights estimated by the stereo-vision imaging system. Moriyuki and Fukuda devised a novel high-throughput diagnosis system using the measurement of chlorophyll fluorescence forming an image of 7200 seedlings acquired by a CDD camera and an automatic transferring machine. They used machine learning in order to extract biological indices and predict plant growth. Previously, Hashimoto et al. (2001) applied an intelligent control system consisting of a decision system based on neuronal networks and genetic algorithms to optimize the growth of hydroponic tomato plants during the seedling stage. Hwang et al. (2014) also proposed a plant factory automatic control system to collect crop image information (illuminance, temperature, humidity, $\mathrm{EC}, \mathrm{pH}$, and $\mathrm{CO} 2$ ) and provided crop environment control and service suitable for crop growth step (crop shape, size, color, and length).

Related to environment controlled and optimization, Zheng et al. explored the effects of different density treatments on potato spatial distribution and yield in spring and fall. They concluded that increased density significantly increased potato yield, but the degree of influence associated with different growing seasons differed slightly. In Japan, there were 165 plant factories with artificial lighting (Kozai et al., 2015). Wang et al. added an air exchanger for cooling in plant production systems with artificial light (PPAL). They found that using air exchanger to introduce outdoor cold air is as an effective way to reduce electric-energy consumption with little effects on plant growth in a PPAL. Besides, the cultivation methods in a plant factory with artificial lighting (PFLA) were studied by Zhang et al., retarded senescence of outer leaves of lettuce and found white LEDs are more appropriate for lettuce growth than red or blue LEDs. In another research, Li et al. applied LED lighting [LED with zoom lenses (Z-LED) and conventional non-lenses LED (C-LED)]. The improvement saved over half of the light source electricity, while the temperature and rate of photosynthesis abruptly decreased, causing reductions in plant yield and nitrate content, while 
having no negative effects on morphological parameters and photosynthetic pigment contents. About nighttime supplemental LED inter-lighting, Tewolde et al. found nighttime LED interlighting can effectively improve tomato plant growth and yield with lower energy cost compared with daytime both in summer and winter. Moreover, Cao et al. achieved that tomato inside of a solar greenhouse increased their fresh weight with the increase of RL NB frequencies. On the other hand, Wang et al. found that leaf photosynthetic capacity and photosynthetic rate increased with decreasing Red/Blue lights ratio until 1. However, shoot dry weight increased with increasing Red/Blue lights ratio with the greatest value under $\mathrm{Red} /$ Blue $=12$ treatment. They concluded that quantitative Blue light could promote photosynthetic performance or growth by stimulating morphological and physiological responses. Miyagi et al. (2017) found that synergistic effects of monochromic LED combined with high $\mathrm{CO}_{2}$ and nutrients would be beneficial alternatives for cultivation of lettuce in the plant factory. Shimokawa et al. (2014) concluded that simultaneous red and blue irradiation promote plant growth more effectively than monochromatic and fluorescent light irradiation. They also found that alternating red and blue light accelerated plant growth significantly even when the total light intensity per day was the same as with simultaneous irradiation. The fresh weight of the plant doubles compared to normal LED cultivation methods. The plant factory can increase harvests and sales using this this method (Showa, 2016).

The production of pharmaceuticals in a plant factory represents an opportunity for health benefits from plants. Flavonoids are a group of plant metabolites thought to provide health benefits through cell signaling pathways and antioxidant effects (Spencer, 2016). Dong et al. studied soluble flavonoids and found that "Xiangfen 1" banana can be a rich source of natural antioxidants in human diets. Jeong et al. (2015) characterized the polyphenolic contents of lettuce leaves grown under different night-time temperatures and cultivation. Plantderived phenylpropanoids (PPPs) compose the largest group of secondary metabolites produced by higher plants (Korkina et al., 2011). Dwivedi et al. reviewed the progress for accessing variation in PPPs in germplasm collections. PPPs are a diverse chemical class with immense health benefits that are biosynthesized from the aromatic amino acid L-phenylalanine.

Genetic engineering of plants deals on the creation of plants to resist herbicides and pests, but also to improve the quality of the crops in terms of consumers (Sévenier et al., 2002). Xing et al. found complex regulatory mechanisms involved in floral induction, flower bud formation, and flowering characteristics, which might reflect the genetic variation of the flowering gene and their data provided a foundation for the further exploration of apple diversity and gene-phenotype relationships, and for future research on molecular breeding to improve apple and related species. Higashi et al. studied circadian oscillation of the lettuce transcriptome under constant light and lightdark conditions and found gene expression pattern is related to photosynthesis and optical response performs normally in lettuce. Higashi et al. detected diurnal variation of tomato transcriptome through the molecular timetable method in a sunlight-type plant factory. They found circadian clock mediate the optimization for fluctuating environments in the field and it has possibilities to enhance resistibility to stress and floral induction by controlling circadian clock through light supplement and temperature control. Tanigaki et al. (2016) in their research suggested that the regulation of gating stomata does not depend predominantly on TOC1 and significantly reflects the extracellular environment. Besides, Zhang et al. studied transcriptome analysis of Dendrobium officinale and its application to the identification of genes associated with polysaccharide synthesis valuable clues for identifying candidate genes involved in polysaccharide biosynthesis and elucidating the mechanism of polysaccharide biosynthesis. On the other hand, Hiwasa-Tanase and Ezura reviewed on molecular breeding to create optimized crops: From genetic manipulation to potential applications in plant factories and found that Cost-effectiveness is improved from the use of cultivars that are specifically optimized for closed system cultivation. Lai et al. studied two LcbHLH transcription factors interacting with LcMYB1 in regulating late structural genes of anthocyanin biosynthesis in Nicotiana and Litchi chinensis during anthocyanin accumulation and found LcbHLH1 and LcbHLH3 are essential partner of LcMYB1 in regulating the anthocyanin production in tobacco and probably also in litchi. The LcMYB1-LcbHLH complex enhanced anthocyanin accumulation may associate with activating the transcription of DFR and ANS.

Bacterial biofertilizers can improve plant growth through several different mechanisms: (i) the synthesis of plant nutrients or phytohormones, which can be absorbed by plants, (ii) the mobilization of soil compounds, making them available for the plant to be used as nutrients, (iii) the protection of plants under stressful conditions, thereby counteracting the negative impacts of stress, or (iv) defense against plant pathogens, reducing plant diseases or death (García-Fraile et al., 2015). Kifle and Laing isolated and screened bacteria for their diazotrophic potential and their influence on growth promotion of maize seedlings in greenhouses. They identified that isolates showed significant effect on at least two growth parameters were at species or genera level.

\section{AUTHOR CONTRIBUTIONS}

All authors listed have made substantial, direct, and intellectual contribution to the work, and approved it for publication.

\section{FUNDING}

AL acknowledges support from PAYCIT UANL 2015. JV acknowledges support from CONACYT. HF acknowledges support from Administration of Faculty of Agriculture, Autonomous University of Nuevo Leon.

\section{ACKNOWLEDGMENTS}

As the topic editors, we would like to thank all our colleagues who contributed their articles. We would also like to express our gratitude to the numerous colleagues who contributed to 
the success of this Research topic by acting as reviewers or editors. We are especially grateful for excellent technical support provided by the editorial office and the chief editors. Finally,

\section{REFERENCES}

García-Fraile, P., Menéndez, E., and Rivas, R. (2015). Role of bacterial biofertilizers in agriculture and forestry. AIMS Bioeng. 2, 183-205. doi: 10.3934/bioeng.2015.3.183

Hashimoto, Y., Murase, H., Morimoto, T., and Torii, T. (2001). Intelligent systems for agriculture in Japan. IEEE Control Syst. 21, 71-85. doi: 10.1109/37.954520

Hwang, J., Jeong, H., and Yoe, H. (2014). Study on the plant factory automatic control system according to each crop growth step. Adv. Sci. Technol. Lett. 49, 174-179. doi: 10.14257/astl.2014.49.33

Jeong, S. W., Kim, G. S., Lee, W. S., Kim, Y. H., Kang, N. J., Jin, J. S., et al. (2015). The effects of different night-time temperatures and cultivation durations on the polyphenolic contents of lettuce: application of principal component analysis. J. Adv. Res. 6, 493-499. doi: 10.1016/j.jare.2015.01.004

Korkina, L., Kostyuk, V., De Luca, C., and Pastore, S. (2011). Plant phenylpropanoids as emerging anti-inflammatory agents. Mini Rev. Med. Chem. 11, 823-835. doi: 10.2174/138955711796575489

Kozai, T., Niu, G., and Takagaki, M. (eds.) (2015). Plant Factory: An Indoor Vertical Farming System for Efficient Quality Food Production. Academic Press.

Miyagi, A., Uchimiya, H., and Kawai-Yamada, M. (2017). Synergistic effects of light quality, carbon dioxide and nutrients on metabolite compositions of head lettuce under artificial growth conditions mimicking a plant factory. Food Chem. 218, 561-568. doi: 10.1016/j.foodchem.2016.09.102

Sévenier, R., van der Meer, I. M., Bino, R., and Koops, A. J. (2002). Increased production of nutriments by genetically engineered crops. J. Am. Coll. Nutr. 21(Suppl. 3), 199S-204S. doi: 10.1080/07315724.2002.10719266 we dedicate this book to the memory of Kei Nakaji, Emeritus Professor at Kyushu University, whose devotion to his students and agricultural ecology will be always remembered.

Shimokawa, A., Tonooka, Y., Matsumoto, M., Ara, H., Suzuki, H., Yamauchi, N., et al. (2014). Effect of alternating red and blue light irradiation generated by light emitting diodes on the growth of leaf lettuce. bioRxiv, 003103. doi: 10.1101/003103. Available online at: http://biorxiv.org/content/early/2014/ 02/28/003103.full.pdf+html

Showa, D. (2016). The Shigyo Method for Cultivation. LED Irradiation Optimized for Plant Growth Facilities. Available online at: http://www.sdk.co.jp/english/ products/160/164/13978.html

Spencer, M. (2016). The Need for Balance - Dealing with the Causes of Meniere's. 1st Edn. Smashwords Edition.

Tanigaki, Y, Higashi, T, Takayama, K, Nagano, A. J., Honjo, M. N., and Fukuda, H. (2016). Transcriptome analysis of plant hormone-related tomato (Solanum lycopersicum) genes in a sunlight-type plant Factory. PLoS One 11:e0150788. doi: 10.1371/journal.pone.0150788

Conflict of Interest Statement: The authors declare that the research was conducted in the absence of any commercial or financial relationships that could be construed as a potential conflict of interest.

Copyright (C) 2016 Luna-Maldonado, Vidales-Contreras and Rodríguez-Fuentes. This is an open-access article distributed under the terms of the Creative Commons Attribution License (CC BY). The use, distribution or reproduction in other forums is permitted, provided the original author(s) or licensor are credited and that the original publication in this journal is cited, in accordance with accepted academic practice. No use, distribution or reproduction is permitted which does not comply with these terms. 